\title{
A Comparative Study of Long-term Care Insurance Systems in Japan and Korea
}

\author{
Li Sheng ji ${ }^{1}$ Shi Xinxin ${ }^{1 *}$ \\ ${ }^{1}$ School of Public Administration, Changchun University of Technology, Changchun 130000, China \\ *Corresponding author: SHI Xinxin; E-mail: 1526960044 @qq.com
}

\begin{abstract}
The paper discuss the advantages and disadvantages of the long-term care insurance system in Japan and South Korea, and propose how to improve the long-term care insurance system in China based on the horizontal comparison of the long-term care insurance system in Japan and South Korea from the aspects of insured objects, financing methods and payment methods; The relevant policies and regulations of long-term care insurance system which covering all the elderly people should be established. The paper also proposed the establishment of an effective long-term care insurance financing mode, clear long-term care insurance payment mode and other corresponding enlightenments.
\end{abstract}

Keywords: care insurance, long-term convalescent insurance for the elderly people, long-term care insurance

\section{COMPARISON OF THE DEVELOPMENT OF LONG-TERM NURSING INSURANCE SYSTEM BETWEEN JAPAN AND KOREA}

In order to deal with the problems of elderly people in aging society, the Japanese government specially set up the report called "the Ministry of the Elderly Care Countermeasures " in April 1994. In December of the same year, the report "Building a new elderly care system" was issued, which clearly pointed out the goal of Japan's need to build a new elderly care system by social insurance. After more than 50 reviews, the "Proposal for the Establishment of Care Insurance for the Elderly" was finalized in April 1994 and three bills were introduced by Congress in November of the same year, those are the Nursing Insurance Act, the Nursing insurance Enforcement Act and the Medical Law Amendment Act, all of which are related to Nursing Insurance. After discussions, the Protection Insurance Act was formally passed through Congress in December 1997. In April 2000, the Government of Japan fully implemented the insurance system.

In 2000, Korea's elderly population accounted for more than $7 \%$ of the total population, and the proportion of the elderly over 65 years old reached $7.2 \%$, entering an aging society ${ }^{[1]}$. In order to cope with the rapid aging, South Korea's government held a discussion in January 2000 on the protection of old-age recuperation. In February 2001, the Office of the Prime Minister of State set up the Commission for the Welfare of elderly Care. In July 2002, the Commission for the Welfare of elderly Care provided advice on the establishment of an longterm aging health insurance system. In July 2005, the executive committee of the public aging convalescent security system gradually constructed the long-term convalescent insurance system for the elderly people through three pilot operations. In April 2007, the National Assembly formally adopted the Law on Long-term Health Care Insurance for the Elderly, The long-term convalescent insurance system for the elderly began to be fully implemented in Korea on July 1,2008.

First of all, the construction of long-term nursing insurance system between Japan and South Korea is different ${ }^{[2]}$. After many years of discussion, Japan established an independent and regional insurance system in 2000, while South Korea established a long-term convalescent insurance system for the elderly in 2008 . Secondly, the purpose of introducing long-term care insurance system in Japan and South Korea is all different. In order to separate medical services from long-term convalescent services for the elderly, reduce medical costs and ensure the well-being of the elderly, South Korea has established a long-term convalescent insurance system, but in addition to coping with the problem of aging and rising medical costs, In order to implement the political purpose of consumption tax, the establishment of care insurance system. 


\section{COMPARSION OF THE OBJESTS OF LONG-TERM NURSING INSURANCE BETWEEN JAPAN AND KOREA}

The Japanese nursing insurance can be divided into two types: insured No .1 and insured No .2. Among them, the elderly over 65 years of age are insured under No .1 insurance while the elderly between 45 and 64 years of age are insured under No .2 insurance ${ }^{[3]}$. Insured No .1 people and insured No .2 people are also applicable to the nursing insurance. Among them, insured No .1 people can obtain support services or nursing services according to the level of payment, while insured No .2 people can only obtain support services or nursing services with 16 specific diseases, such as cerebrovascular diseases and early cognitive impairment. Therefore, Japanese nursing insurance is not an inclusive social security system with all Japanese nationals as the applicable object, but a selective security system for certain age and people with specific diseases.

Korean elderly long-term convalescent insurance is insured for all citizens, and the payment is divided into 65 years old and 64 years old with cognitive impairment, cerebrovascular disease, Parkinson's syndrome and other 24 elderly patients. The insurance payment grade is divided into 3 degrees, that is, moderate degree(grade 3 ), severe degree(grade 2), and most severe degree(grade $1)^{[4]}$. However, the Korean long-term convalescent insurance for the elderly who is unable to take care of themselves for long period as the applicable object, but elderly who is unable to take care of themselves in moderate degree were excluded from the scope of insurance.

The comparative analysis shows that Japan and South Korea provide corresponding nursing services to specific groups according to age and specific diseases, but this kind of nursing service shows obvious selective characteristics. There is obvious consistency between the insured people and payment object of Japanese insurance, while there is obvious inconsistenly between the the insured people and the payment object of Korean elderly long-term convalescent insurance.

\section{COMPARISO NOF FIANCING METHODS OF LONG-TERM CARE INSURANCE BETWEEN JAPAN AND KOREA}

Among Japan's total cost of insurance, there is $10 \%$ personal burden and $90 \%$ insurance burden. $90 \%$ of the total cost of the insurance is covered by $50 \%$ of the insurance and $50 \%$ of national treasure among which No.1 insured people pay $22 \%$ insurance fee and No .2 insured people pay $28 \%$ insurance fee. Among the treasury burden, the central government of Japan pays 25 percent (including 20 percent of the central government and 5 percent of state adjustment payments), the city's government burden of 12.5 percent, and the country's government burden of 12.5 percent. Japan's central government's $5 \%$ national adjustment payments were set to adjust the financial gap between the cities and countries.

Korea's National Health Insurance Corporation collects long-term health insurance fee and health insurance fee for the elderly people contemporarily, among which elderly long-term convalescent insurance payment rate times national health insurance fee is elderly long-term insurance fee. In the long-term convalescent insurance fee for the elderly, the treasury pays $20 \%$, the Korean government pays $20 \%$ of the expected long-term convalescent insurance income from the treasury as the nursing insurance fee, the long-term convalescent insurance burden is $60 \%$ and the personal burden is $20 \%$. When Korean people obtain institutional services, they need to pay $20 \%$. At the same time, the individual needs to pay the living expenses and food expenses of the institution, while the of home service requires $15 \%$ of the expenses. However , $50 \%$ of the personal burden can be reduced for recipients of medical services, low-income persons and insured persons receiving the minimum subsistence allowance.

It can be concluded from the comparative analysis that the Japanese government pays $50 \%$ of the insurance fee with public finance, the central government: Dudaofu County: the City Village pays half of the insurance cost at 2:1:1. Japanese insurance reflects the characteristics of higher national financial support and lower personal burden. The Korean government only pays $20 \%$ of the insurance fee and the individual pays $80 \%$ of the insurance fee. The Korean long-term convalescent insurance reflects the characteristics of lower national financial support and higher personal burden.

\section{COMPARISON OF LONG-TERM NURSING INSURANCE PAYMENT METHODS BETWEEN JAPAN AND KOREA}

Japan's nursing insurance can be divided into two types: prevention payment and care payment. It also can be divided into home service, institutional service and community service. The support person can only use the home care service, and the organization care service object is the 3-7 level insured person who wants to be protected, as long as get the care identification, can use the home care service. Home-based services provide 11 types of home-based care services, such as visiting care, visiting bath care, visiting care, visiting rehabilitation training, day facility care, welfare equipment rental, living short-term care, convalescent short-term care, home-based care management guidance, and life-based care for persons with specific facilities. Community services provide regular visit care, night visit care, day 
dementia care, small-scale multi-functional home services, dementia corresponding co-living care, community-specific living care, community elderly welfare facilities services, complex services and other eight kinds of community care services. Institutional services provide three kinds of institutional care services, such as health care facilities for the elderly, health care facilities for the elderly and medical facilities for nursing and recuperation.

There are three types of long-term convalescent insurance in Korea: institutional service, special cash payment and home service. Home services provide access services, access to bath services, access care, weekly night care, short-term protection, welfare equipment rental and other six care services. Institutional services provide three kinds of nursing services, such as the elderly convalescent facilities, the elderly special convalescent facilities, and the elderly convalescent living together. Special cash payment includes family recuperation fee, special recuperation fee, convalescent hospital recuperation fee and so on. Among them, the insured people with 1-2 grade can choose home service or institutional service, while the insured people with 3 grade can only choose home service.

South Korea long-term convalescent insurance has two forms of payments including providing services and cash payments. In principle, long-term convalescent institutions provide corresponding convalescent services according to the level of payment of insured persons. Although there are three kinds of special cash payment way, South Korea only provides family recuperation fee at present. For remote or difficult areas, long-term convalescent agencies provide insured persons with family recuperation fees.

Comparative analysis shows that both countries provide long-term care services. South Korea provides limited cash payments; Japan provides medical services such as visiting convalescent hospitals, while visiting care is provided in the home service in Korea; Japan provides a variety of preventive care services, while South Korea provides less care services and cash payments based on basic convalescent protection.

\section{CONCLUSION}

THE ENLIGHTENMENT OF THE CONSTRUCTION OF LONG-TERM NURSING INSURANCE SYSTEM IN JAPAN AND SOUTH KOREA TO CHINA

\subsection{Improving the Policies and Regulations Related to Long-term Nursing Insurance System}

Based on the long-term nursing insurance law, Japan and South Korea not only guarantee the standardization, institutionalization and legalization of the long-term nursing insurance system, but also provide a strong legal guarantee for the long-term and stable operation of the long-term nursing insurance system ${ }^{[5]}$. Since 2016, the long-term nursing insurance system has been running in China for more than 4 years, and the policies and regulations related to long-term nursing insurance should be further improved. The "notice" and "opinion" related to long-term nursing insurance are raised to the legal level so that the long-term nursing insurance law for the elderly is formulated. According to the law, the operation mode, the source of funds, the application process, the insured object, the payment method and nursing insurance can provide guarantee for the stable operation of long-term nursing insurance system in China.

\subsection{Establishment of a long-term care insurance system covering all elderly persons}

Japan and South Korea have included the elderly over 65 years of age in long-term care insurance to provide long-term care services for the elderly people, and both countries have realized the socialization of caring for the elderly ${ }^{[6]}$. As early as 2000, China entered an aging society, and the family problem of caring for the elderly gradually developed into a social problem. Therefore, China needs to establish a long-term nursing insurance system based on national conditions as soon as possible. Both Japan and South Korea belong to the Confucian cultural circle, and their experience in establishing longterm nursing insurance system has important reference for our country. China can refer to the practice of establishing and polishing the long-term nursing insurance system in Japan and South Korea, and establish a long-term nursing insurance system which covering all the elderly by social insurance, and realize the socialization of caring for the elderly. It can not only lighten the burden of family care, but also improve the quality of life of the elderly.

\subsection{Establishing sound financing methods for long-term care insurance}

Japan and South Korea have established a long-term nursing insurance system in the form of social insurance ${ }^{[7]}$. Both countries collect certain insurance fee according to personal income level as one of the funding sources for long-term care insurance Japan and South.

\subsection{Clarifying the mode of payment of long-term care insurance}

Japan and Korea long-term care insurances follow the principle of providing services as the main way to provide treatment benefits, Korea also provides part of the cash payment. China can learn from the experience of Japan and South Korea implement the payment services which supplemented by cash payment. According to the result 
of long-term nursing insurance demand grade, the insured people are provided with the corresponding level of nursing service. At the same time, clear control of insurance fee, each insured person set a corresponding payment top line.

\section{ACKNOWLEDGMENTS}

From the beginning of the topic selection to the final conclusion of this paper, we need to thank the relevant scholars for their careful research. At the same time, I would like to thank the organizer of the conference for providing me with this opportunity. This paper was supported by the Social Science Planning Project of the Ministry of Education (Project Approval No: JJKH20200692SK).

\section{ABOUT THE AUTHOR}

Li Shengji (1986-), male, born in Yongji, Jilin, associate professor, School of Public Administration, Changchun University of Technology, research direction: labor economy.

Shi Xinxin (1995-), female, born in Baoding, Hebei Province, master student of School of Public Administration, Changchun University of Technology, research direction: Administration.

\section{REFERENCES}

[1] Cui Yongxun. Comparison of Long-term Care Insurance System for the Elderly in Japan and South Korea [J]. Korean Policy Studies, 2011 (11): 351 366.

[2] Park Yoon Ja,Kang Young Sook. Comparative study of long-term care insurance system for the elderly in Japan and Korea [J].Japanese Cultural Studies, 2013 (45) : 173-192.

[3] Zhang XJ, Zhu K. Japan's long-term care policy and its enlightenment to China [J]. China Health Policy Research, 2014 (4): 5-61. (in Chinese)

[4] Journal of China Youth University for Political Sciences, 2011 (4) : 89-94.] [Yang Y, Yang Y, Yang $\mathrm{Y}$, et al.Comparison of nursing insurance system between Japan and South Korea and its enlightenment $[\mathrm{J}]$. Journal of China Youth University for Political Sciences, 2011 (4): 89-94.]

[5] Chunjiang Zhao, Jinxia Sun. The reform of long-term care insurance system in Japan and its enlightenment [J]. Population Journal, 2018, 40(01):79-89.

[6] Yuan Xin, Liu Huiru. Comparison of Long-term Care Insurance System in Japan and Germany and Its Reference [J].Journal of Japanese Studies, 2019, 33(03): 64-72.
[7] Analysis of long-term care insurance system in South Korea [J]. Northeast Asia Journal, 2019(03): 118131+151-152. (in Chinese) 